\title{
A non-traumatic approach to ventral subarachnoid space near circle of Willis
}

\author{
P.S. Lacy * \\ Department of Anatomy and Cell Biology, University of Michigan Medical School, Ann Arbor, MI 48109-0010 (U.S.A.)
}

(Received 22 February 1988)

(Revised 25 May 1988)

(Accepted 5 June 1988)

Key words: Berry aneurysm; Subarachnoid hemorrhage; Cannulation; Parenchymal injury; Vasospasm

\begin{abstract}
A non-traumatic approach to the subarachnoid space near the circle of Willis is demonstrated in this study. The approach is made between the olfactory bulb and frontal lobe. Following perfusion with Evans blue dye no leakage was observed into the parenchyma indicating no tissue damage had occurred. No gross bleeding or cerebral vasospasm was visible in the middle meningeal artery (dural), the surface pial blood vessels and the vessels of the circle of Willis. In conclusion, this technique can be successfully used for studies on experimental subarachnoid hemorrhage simulated on the ventral aspect of the brain near the circle of Willis without causing technique-associated cerebrovascular and parenchymal injury.
\end{abstract}

\section{Introduction}

In order to simulate a subarachnoid hemorrhage (SAH) in laboratory animals, the techniques employed have introduced blood in the subarachnoid space over the parietal (Hawkins and Clower, 1971) parieto-occipital (Estanol et al., 1977), occipital (Offerhaus and Van Gool, 1969) regions and in the cisterna magna (Pickard and Perry, 1984; Uemura et al., 1986). Radio opaque catheters have also been used (Estanol et al., 1977). The approach to the circle of Willis which is often the site of berry aneurysms has been transorbital through the optic foramen (Clower et al., 1980) and through a hole in the midline of the skull of the Rhesus monkey cephalad to the nasion, directing blood along the floor of the anterior fossa

\footnotetext{
* Present address: University of Osteopathic Medicine and Health Sciences, Department of Anatomy, 3200 Grand Avenue, Des Moines, IA 50312, U.S.A.

Correspondence: P.S. Lacy, Department of Anatomy and Cell Biology, University of Michigan Medical School, Ann Arbor, MI 48109-0010, U.S.A.
}

under the area of the circle of Willis (McIntyre et al., 1971). Another approach to the ventral subarachnoid space has been to inject blood via a cannula that was led alongside the left lateral surface of the brain towards the circle of Willis (Lacy and Earle, 1983). However, none of the studies have explored the possibility that cerebrovascular and parenchymal injury may occur due to the technique itself, especially in studies where $\mathrm{SAH}$ is simulated under the ventral surface of the brain near the circle of Willis.

This study demonstrates cannulation of the ventral subarachnoid space near the circle of Willis which can be done without causing acute cerebrovascular and parenchymal injury.

\section{Materials and Methods}

Ten Wistar-Kyoto rats weighing between 350 and $400 \mathrm{~g}$ each were anesthetized with $40 \mathrm{mg} / \mathrm{kg}$ ketamine given i.m. Each animal was placed in a stereotaxic apparatus and a $1 \mathrm{~mm}$ burr hole was drilled in the left frontal bone at its widest point 

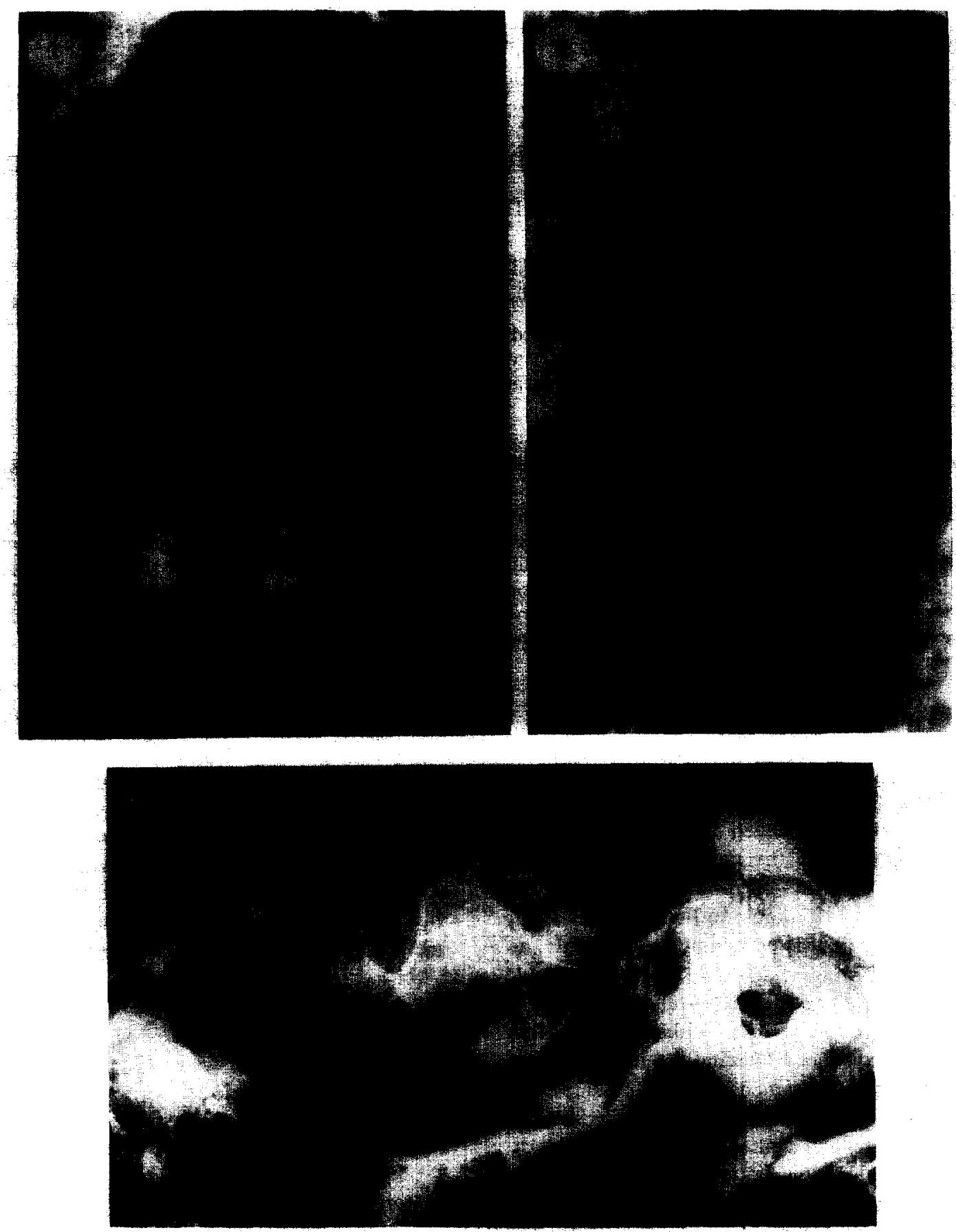

Fig. 1. Rat skull showing position of burr hole (A) at widest point in left lateral frontal bone through which silastic tubing (B) is introduced into subarachnoid space.

Fig. 2. Rat brain showing position of the space between junction of olfactory lobe and frontal lobe (A) on the left side through which silastic tubing (B) is passing.

Fig. 3. Left lateral aspect of rat brain showing where tip of cannula (A) rests in subarachnoid space near circle of Willis as seen through a tear in dura mater (B). Route of cannula (C) in subarachnoid space seen through overlying dura mater. No vasoconstriction in middle cerebral artery (D) and no leakage of Evans blue is visible in brain parenchyma. Tortuous course of middle meningeal artery $(E)$ which appears patent in dura mater. 
as shown in Fig. 1. The position of the burr hole was approximately $10 \mathrm{~mm}$ anterior to the interaural line on the dorsal surface of the skull. The hole was approximately $3.4 \mathrm{~mm}$ lateral to the midsagittal line. The position of the hole corresponds to the junction of the olfactory lobe and the frontal lobe (Fig. 2). Approximately $1.6 \mathrm{~cm}$ was marked on a $15 \mathrm{~cm}$ long piece of silastic tubing of 0.02 inch i.d, and 0.037 inch o.d. The silastic tubing was manually directed through the burr hole (Fig. 1) between the junction of the olfactory lobe and frontal lobe (Fig. 2), pushed to the base of the skull (Fig. 3) and then maneuvered posteromedially towards the circle of Willis (Fig. 3) till

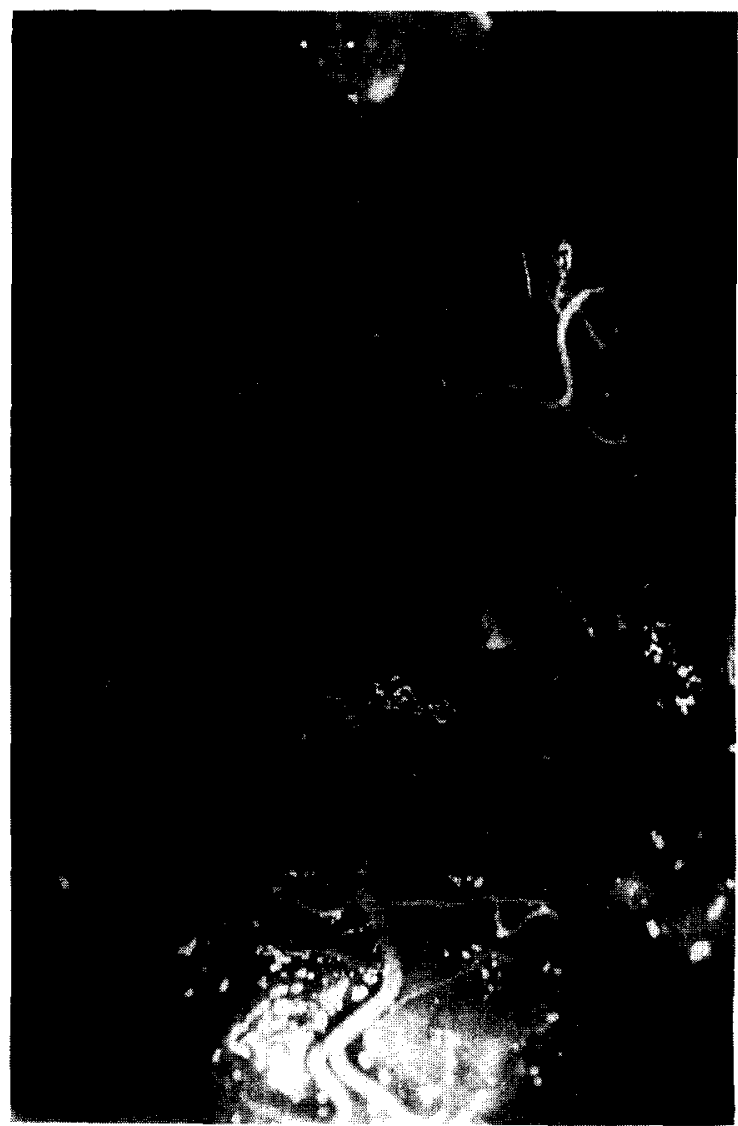

Fig. 4. No leakage of Evans blue dye is visible on ventral aspect of brain following cannulation of ventral subarachnoid space. Vessels of the circle of Willis are symmetrically filled with opaque marker on both sides. Arrow points to cut end of left internal carotid artery which appears similar in contour to the right side.
$1.6 \mathrm{~cm}$ of the tubing had been pushed in. Immediately following cannulation $1 \mathrm{ml}$ of $2 \%$ Evans blue was injected through the femoral vein and allowed to circulate for $20 \mathrm{~min}$. The brains were then fixed with aldehyde by perfusion through the left ventricle with an 18-gauge needle and the vasculature was infused with an opaque marker medium to fill the arterial bed as previously described (Jokelainen et al., 1980) using a Harvard pump to maintain normal physiological pressure.

\section{Results}

On necropsy the tip of the cannula was identified under the circle of Willis in 7 out of 10 animals. Of the remaining 3 animals, the tip of the cannula had entered brain tissue in one animal and had turned towards the orbit in the other two animals. Although the cannula had been closely applied to the left lateral surface of the skull, no leakage of Evans blue, no bleeding and no vasospasm was observed on the left lateral surface of the brain (Fig. 3) along the cannulation route. The vessels of the circle of Willis also showed no focal vasospasm on the left side (Fig. 4).

\section{Discussion}

The technique demonstrated in this study takes advantage of the widest part of the frontal bone as an external landmark for making a burr hole, and the space between the olfactory lobe and frontal lobe for passage of the silastic tubing. The inner left lateral surface of the skull is used for guidance of the cannula till it touches the base of the skull. The remaining part of the procedure, i.e. guiding the cannula posteromedially towards the circle of Willis is aided immensely by bearing in mind the position of the circle of Willis in relationship to the burr hole.

This technique can be useful for simulating the rupture of a berry aneurysm near the circle of Willis and for experimental studies of associated problems, namely electrocardiographic abnormalities (Lacy and Earle, 1983), myocardial damage (Hawkins and Clower, 1971), reactivity of cerebral 
vessels (Pickard and Perry, 1984; Uemura et al., 1986), morphological changes in cerebral vessels (Liszczak et al., 1984; Pickard and Perry, 1984; Takemae, 1984), cerebral vasospasm (Symon, 1971), hypothalamic lesions (Crompton, 1963), cerebral infarction (Crompton, 1964), and the role of possible risk factors, e.g. diabetes mellitus (Kurtzke, 1983) with regard to a subarachnoid hemorrhage.

\section{Acknowledgements}

The help given by Mr. W.L. Brudon, Mr. Uldis Ilvess and Ms. Donna Miler with the illustrations is gratefully acknowledged.

\section{References}

Clower, B.R., Smith, R.R, and Peeler, D.F. (1980) Responses of the autonomic nervous system to subarachnoid hemorrhage, Anat. Rec., 196: 34A.

Crompton, M.R. (1963) Hypothalamic lesions following the rupture of cerebral berry aneurysms, Brain, 83: 301-314.

Crompton, M.R. (1964) The pathogenesis of cerebral infarction following the rupture of cerebral berry aneurysms, Brain, 87: 491-510.

Estanol, B.V., Loyo, M.V., Mateos, J.H., Foyo, E., Cornejo, A. and Guavara, J. (1977) Cardiac arrhythmias in experimental subarachnoid hemorrhage, Stroke, 8: 440-447.

Hawkins, W.E. and Clower, B.R. (1971) Myocardial damage after head trauma and simulated intracranial hemorrhage in mice: the role of the autonomic nervous system. Cardiovasc. Res., 5: 524-529.

Jokelainen, P.T., Webb, D.R. and Yush, E.D. (1980) A com- bined electron microscopic microangiographic methodology for cerebrovascular studies, J. Ultrastruct Res., 71 . 116-125.

Kurtzke, J.F. (1983) Epidemiology and risk factors in thrombotic brain infarction. In M.J.G. Harrison and M.L. Dyken (Eds.), Cerebral Vascular Disease, Butterworth, London, pp. 27-45.

Lacy, P.S. and Earle, A.M. (1983) A small animal model for electrocardiographic abnormalities observed after an experimental subarachnoid hemorrhage, Stroke, 14: 371-377.

Liszczak, T.M., McL. Black, P., Tzouras, A., Foley, L. and Zervas, N.T. (1984) Morphological changes of the basilar artery, ventricles and choroid plexus after experimental SAH, J. Neurosurg., 61: 486-493.

McIntyre, J.W.R., Dobson, D., Weir, B.K.A., West. R. and Overton, T.R. (1971) Monitoring under anesthesia, with reference to subarachnoid hemorrhage and the $T$-wave as an electrocardiographic manifestation, Canad. Anaesth. Soc. J., 18: 293-297.

Offerhaus, L. and Van Gool, J. (1969) Electrocardiographic changes and tissue catecholamines in experimental subarachnoid hemorrhage, Cardiovasc. Res., 3: 433-440.

Pickard, J.D. and Perry, S. (1984) Spectrum of altered reactivity of isolated cerebral arteries following subarachnoid hemorrhage - response to potassium, $\mathrm{pH}$, noradrenaline, 5-hydroxytryptamine, and sodium loading, J. Cereb. Blood Flow Metabol, 4: 599-609.

Symon, L. (1971) Vasospasm in aneurysm. In J. Moosy and R Janeway (Eds.), Cerebral Vascular Diseases, Grune and Stratton, New York, pp. 232-240.

Takemae, T., Branson, P.J. and Alksne, J.F. (1984) Intimal proliferation of cerebral arteries after subarachnoid blood injection in pigs, J. Neurosurg., 61: 494-500.

Uemura, T., Sugimoto, T., Okamota, S., Handa H. and Mizuno, N. (1986) Changes of vasocative intestinal polypeptide-like immunoreactivity in cerebrovascular nerve fibers after subarachnoid hemorrhage: and experimental study in the dog. Neurosci. Lett.; 71: 137-141. 